\title{
GUIDELINES FOR COLLABORATION BETWEEN GERIATRIC PHYSICIANS AND PSYCHIATRISTS IN THE CARE OF THE ELDERLY*
}

1. Services for the elderly should be a unity for 'consumers' (i.e. patients, families, referrers). Patients should not be bounced back from one part of the service merely because they seem more appropriate for another part; such redistribution of referrals should be the internal responsibility of the service.

2. 'Unity' does not mean blurring of the specificity of particular professions and facilities within the service and the patient's right of access to them.

3. Criteria for division of responsibility must be clear, and must be known and accepted both inside and outside the service.

4. Effective collaboration depends on mutual confidence, and often frankly on personal friendships. Trust is indispensable, and people should be able at times to accept each other's judgements about their own responsibilities.

5. Mutual confidence requires basic education in each other's disciplines. Implementation of the sort of reciprocal training schemes which have been proposed at the Standing Joint Committee of the BGS and RCPsych is urgent.

6. The Statutory Instrument for the appointment of consultants allows employing Authorities to invite representation of other relevant specialties on Advisory Appointments Committees. It is always desirable that the local geriatric physician or geriatric psychiatrist should be on the Appointments Committee for his opposite number.

7. Responsibility should be determined by the assessed needs of the patient, and not by quirks of referral. For example, if a patient with a gross motor stroke is referred to a psychiatrist, he is no less the responsibility of the medical services through having first made contact with the psychiatrist; and vice versa with a patient with severe depression.

8. Lack of resources does not alter the definition of responsibility. Once a patient's needs are recognized as falling within the province of one service, that service should support the patient within the limits of the feasible-even if this is less than ideal; a 'psychiatric' patient does not become 'geriatric' simply because there are no psychiatric beds or vice versa.

- Drafted by Professor T. Arie agreed by the Standing Joint Committee of the British Geriatric Society and the Royal College of Psychiatrists.
9. Despite the foregoing, there are patients who fall in a 'grey' area where they might appropriately be dealt with by either service. This then becomes a matter of negotiation between the two services, but the service which first made contact retains responsibility until ultimate placement is agreed. Patients must never be allowed to 'fall between two stools'.

10. The principle that responsibility is determined by the patient's needs applies equally to patients admitted under compulsory orders. A patient admitted under the Mental Health Act may occasionally need direct admission to a medical (or surgical) bed, and a patient admitted under the National Assistance Act to a psychiatric bed. The belief that an elderly patient who is admitted under compulsion will necessarily be disruptive or insist on leaving is understandable but mistaken. There is rarely difficulty with such patients in general wards.

11. Criteria for division of responsibility in 'Services for Mental Illness Related to Old Age' (HM(72)71) are broadly satisfactory, though the references there to the presence or absence of 'significant physical disease or illness' may cause difticulties if common sense is not applied.

12. Experience suggests that the best criterion for the placement of demented patients needing longer term care is whether they are ambulant or not, always provided there is the flexibility necessary for the odd case that does not fit.

13. 'Severe dementia' is used as a criterion in $H M(72) 71$, but this can be misleading if interpreted merely in a cognitive sense. The issue turns on the presence and nature of behaviour disturbances associated with dementia and these may be severe in a 'mildly' demented patient, and absent in a 'severely' demented patient.

14. Practice in regard to the establishment of Joint Units, or Psycho-Geriatric Assessment Units, as recommended in $H M(70) 11$, varies from District to District. Where geriatric psychiatry and geriatrics are side by side in a District General Hospital it may not be necessary to establish a separate Joint Unit. Joint care does not depend on fixed assignment of joint beds, still less on separate joint units, though these are often desirable, especially when geriatric physician and geriatric psychiatrist have their headquarters in 
different hospitals. The basic principles of joint care are that patients assessed by one service as needing joint care of both should receive it; that each service should have direct access to joint care; and that 'exit responsibility' should, as in all other situations, depend on the assessed needs of the patient rather than merely on who arranged the original admission.
15. Patients with a psychiatric history who develop physical illness or gross physical deterioration at home, should be reassessed again. No one should be labelled as 'a psychiatric patient' by virtue merely of some previous psychiatric episode; and vice versa for patients with previous physical illnesses who develop psychiatric disorders.

\section{AMENDMENTS TO "REGULATIONS FOR THE MEMBERSHIP EXAMINATION"}

The following amendments to the regulations for the membership examination have been made:

Paragraph 1: Line 2-for Edinburgh read Glasgow.

Paragraph 3: Add the following sentence: January 1980 any doctor who is not registered in the United Kingdom or Republic of Ireland as described above, and who holds any other qualification, will only be accepted as a candidate for the Examination (including the Preliminary Test) if he produces evidence that he is eligible to sit the Professional and Linguistics Assessments Board Examination (PLAB) or has been granted exemption from it, or has passed it.

Paragraph 6: Should now read:

Exemptions granted to candidates before 16th June 1973 remained valid for a period of five years from the date of granting. All candidates who failed to pass the Membership Examination within that period have now forfeited their exemption and must pass the Preliminary Test before proceeding to the Membership Examination.

Paragraph 7: For Clinical Tutor read Psychiatric Tutor.

Paragraph 9: For Clinical Tutor read Psychiatric Tutor.
The Court of Electors has decided that from 1st

Paragraph 14: Add the following sentence: The maximum period that is allowed for such training is one year except for those candidates who provide documentary evidence that they have trained in psychiatric posts approved by the Royal College of Physicians and Surgeons of Canada, the American Board of Psychiatry and Neurology, or the Royal Australian and New Zealand College of Psychiatrists, who will be given credit for the whole of this period of training.

Paragraph 18: Add the following:

(See also paragraph 3.)

Paragraph 31: Omit the words of $£ 20$.

Paragraph 32: Delete paragraph concerning interim certificate and substitute the following: Laughlin Prize-a prize of $£ 50$ will be awarded twice a year in the Spring and Autumn to the candidate who obtains the highest marks and the best recommendation from the Examiners in the Membership Examination.

The Research Option (Notes): Add a further Note (4):

(4) Candidates who wish to have further advice about this may contact the Chairman or Secretary of the Research Committee at the College.

Thomas BeWLeY Dean

\section{THE LIBRARY}

A whole series of problems have delayed the reopening of the Library, not the least of which has been the physical movement of the books stacked temporarily in the basement.

Thanks largely to Dr. Alexander Walk's help, the lion's share of the books is now in situ, but additional shelving is required before further books can be moved. The position is further complicated by the fact that the workmen are about to start on the redevelopment of the basement so that those books which are at the moment stored there will have to be temporarily moved elsewhere.

However, I feel it is imperative that members should enjoy what the Library has to offer even if the facilities at this juncture are somewhat limited. I propose, therefore, that any member should have access to the Library, but in the interests of security prior arrangements should be made. Would members, therefore, kindly telephone the College (01-235-2351) in advance?

It is regretted that there are no facilities as yet for borrowing books, although it is sincerely hoped that this will not be long delayed.

H. R. Rollin, Librarian 